\title{
Fundamentals of Brain Tumour Detection - Models and Error Processing Methods
}

\author{
Michal Kvet ${ }^{1} \&$ Karol Matiaško ${ }^{1}$ \\ ${ }^{1}$ Department of Informatics, Faculty of Management Science and Informatics, University of Žilina, Žilina, \\ Slovakia \\ Correspondence: Michal Kvet, Department of Informatics, Faculty of Management Science and Informatics, \\ University of Žilina, Žilina, Slovakia. E-mail: Michal.Kvet@fri.uniza.sk, Karol.Matiasko@fri.uniza.sk
}

Received: August 30, 2013 Accepted: October 18, 2013 Online Published: January 2, 2014

doi:10.5539/cis.v7n1p67

URL: http://dx.doi.org/10.5539/cis.v7n1p67

\begin{abstract}
The field of medicine is one of the most important spheres of the current research. The aim of the paper is to develop new and improve existing diagnostic techniques and related therapies methods. Cancer in any form is a serious disease and often results in death of the patient. This paper deals with the principles of modelling and visualization of the brain anomaly or tumour in connection with the detection and localization of anomalies. The project focuses on detecting brain anomalies based on specific brain tumour markers present in the cells, but is independent and can be used in the detection of tumors in any organ of the human body. This paper also deals with the problems of processing the results of magnetic resonance, where the results of the measurement can be inaccurate - the error rate of the processing is relatively high. In this case, these data may be considered as incorrect and must be processed (replaced) to get more reliable and relevant values. The last part describes the advantages of the proposed solution in comparison with other applications, its limitations as well as the new modules, which could improve and extend the implemented application.
\end{abstract}

Keywords: tumour, marker, error processing, model, localization, visualization, MRI

\section{Introduction}

Research in any area of life is important. The importance of medical research is based on the fact, that it touches everyone in some way. Application of new knowledge and technical innovations into standard medical practice can expand diagnostic and therapeutic methods, which can improve the treatment of the patient.

Cancer is one of the most serious problems of current medicine. It primarily affects the patient's life, but also its surroundings and society. The aim of many medicine professionals is to improve diagnostic and treatment methods. Adequate treatment of early diagnosed disease gives patients the possibility of becoming healthy, it improves the quality of life and increases the possibility to return to common life and, of course, reduces the cost of treatment.
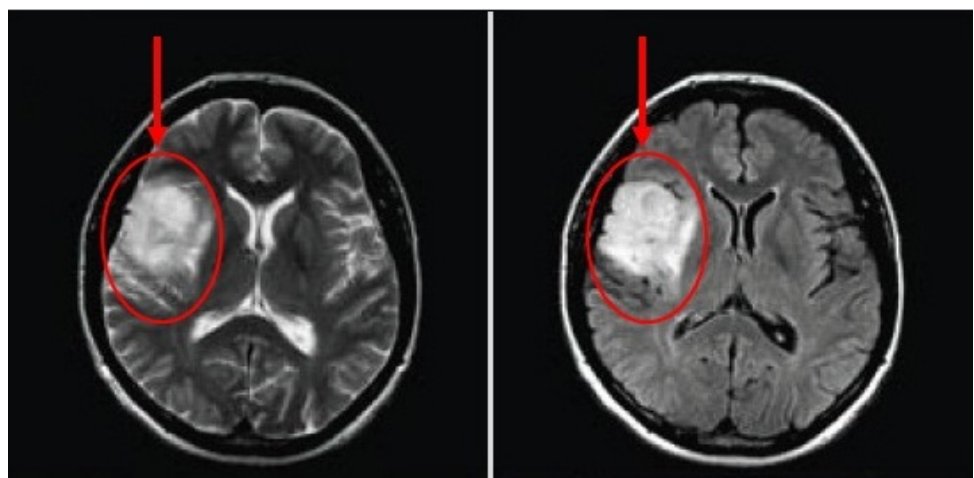

Figure 1. Brain tumour (http://www.mri-portal.com/verejnost.php $\quad$ [On-line 5.8.2013]) 
Our project is medically oriented and based on doctors' requirements. The basis of the project is to cooperate with the Faculty Hospital in Martin.

The aim of our project is to detect, locate, and visualize a brain tumour. Thus, doctors can easily interpret the results of magnetic resonance imaging (MRI). All anomalies are colourly displayed and modelled. Our application offers a variety of display modes - 3D model of the head, a 2D model and charts. It also gives the possibility of calculating undefined, respectively incorrectly measured voxels in the part of the brain. Voxel is a term referring a spatial element image. Unlike pixel covering a two-dimensional image, the term voxel is used in three-dimensional models; it is displayed as a cube and has equivalent features as pixel. The main reason for the development of the new system is currently inadequate solutions. Specifically, there are some solutions, mostly based on the DICOM data processing, but there is no possibility for automatic tumour cells processing and detecting. Developed system should not only detect and locate anomalies, but should also compare the results of the patient during the time, score the treatment and prognoses results. Last but not least aim is to monitor patient to find correlactions between markers and specific diagnoses.

Measurement error processing and the possibility of its reduction are considered a key part of the project. The main factor in the quality of the output results is the reliability of the data processing. An essential part of the problem is to eliminate all incorrectly measured data - noise based on various criteria with a clear objective - to obtain relevant and reliable data for further processing. This area is currently processed by the doctor without the support of specialized decision-making applications.

Methodology could be used prospectively in the diagnosis of other diseases affecting the brain.

\section{Ease of Use \& History}

Engineering project - information system for a hospital was established in 2009 based on the long-term cooperation with the University Hospital in Martin (Slovakia). The aim of this project is to create complex system for the hospital staff, develop and improve existing applications according to their requirements. This project is directly linked to the practical usage. The first part of the project was a modular system for ambulances to form unified communication, data processing and simplify the process of data management. Later, in September 2010, a new part of the project was dedicated to the detection of brain tumour.

Initial phases of this project were based on digital images. However, after thoroughly studying the issue, consulting with experts, and considering available methods, we stopped the development in this sphere due to bad results, although the used methods were complex and difficult to manipulate. In addition, proper results cannot be based of the visual component. The output files of examination of the patient do not consist of only digital images, but also additional files containing values of the special substances. There are several special programs for processing the results of magnetic resonance imaging; some of them are mentioned in the next rows.

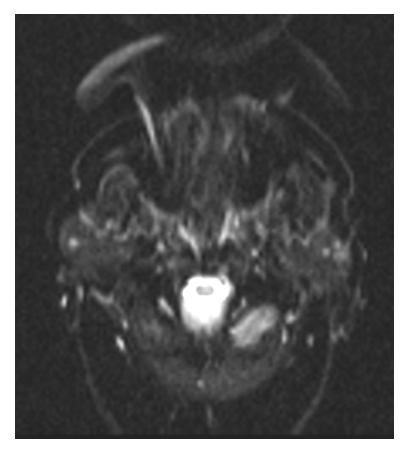

Figure 2. Quality of the input material - digital images

\section{1 jSIPRO}

Spectroscopic imaging (SI) usually contains a large number of spectra to be processed, analyzed and interpreted. Producers of the scanners solve this problem by installing various SI packages directly to the scanner. However, these packages are primarily intended for use in clinical practice and offer limited functionality. Specialized tools were developed to enable SI data processing. However, these tools are mainly focused on sophisticated spectral processing and offer only limited support for the analysis of the calculated spectroscopic maps. 
Platform jSIPRO is an independent graphical interface for pre-processing, post-processing, review, analysis and reporting of the resulting SI data. It is the successor of CULICH and is developed on the Java platform. There is also available an interactive image processing with spectroscopic grid overlay, showing localized images and also protocol-driven batch processing. Input formats are based on Siemens DICOM (VB15, VB17) and GE. Sdf. SHG (SAGE header version 2.6) two-dimensional and three-dimensional data sets SI. It also allows multi-user access to data, which can be shared among different users jSIPRO. (Horvat, 2003; Hornak, 2008)

It does not contain built-in program for editing. Instead, it uses applications of third side for data flow management. Parameter processing and automatic processing of spectra provides LCModel (described later), Tarquini and jMRUI. Spectra for each voxel of spectroscopic gratings are processed separately to leverage parallel processing spectra.

Each calculated data layer displays concentration and error values, processed spectra patterns of metabolites and variety of parametric maps. It is possible to view interactive conditional metabolic images depending on the values of the selected parametric maps. Calculated concentrations can be corrected through various types. There are fixes available through relaxation, partial volume correction, or a user-defined correction. Partial volume corrections (in the brain) are based on segmentation maps, white and gray matter.

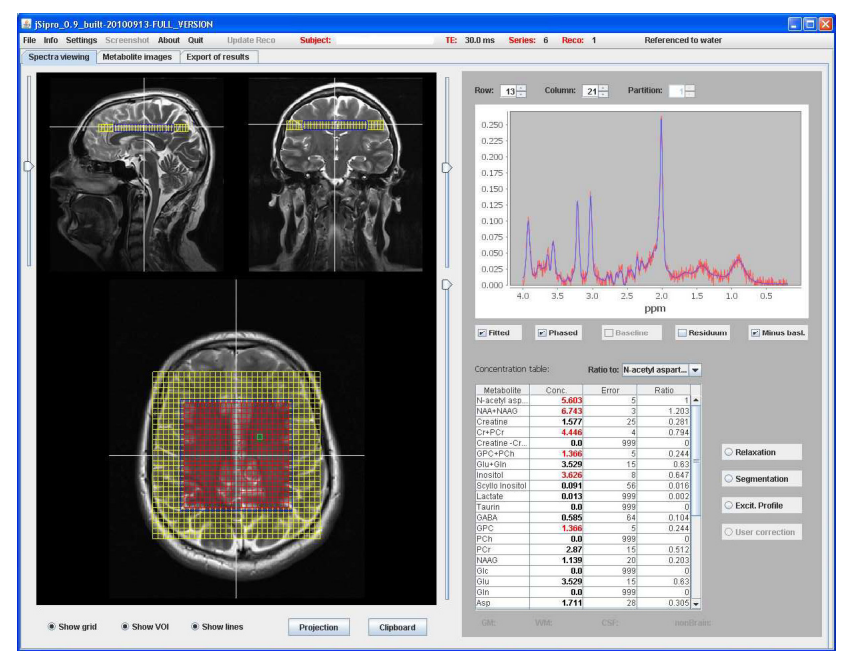

Figure 3. jSIPRO

\subsection{LCModel}

LCModel is an editing tool designed to narrow spectral range of known spectral properties "in vivo" spectrum. Data analysis can be performed on one or more MR spectroscopic voxels displayed data sets.

This tool provides preprocessing to be used in instruments such as jSIPRO in our application. This is very expensive and difficult computational complexity of the software. Licenses are sold for a single computer and thus hospitals with limited budgets must often wait for a long time to process a particular examination (Hornak, 2008; Dobeš, 2008; Pianykh, 2008). 


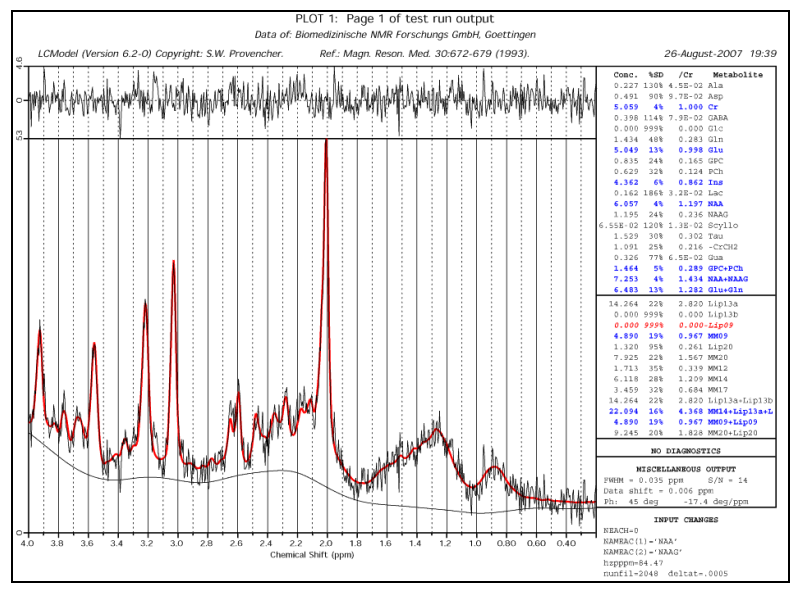

Figure 4. LCModel

\subsection{Syngo fastView}

Syngo fastView (created by Siemens) is a separate DICOM browser provided on DICOM exchange media. It may be used on any computer running Windows, but is not authorized for medical offices. The operating concept is based on a simple usage and follows the Syngo philosophy: "Learn one - know everything".

It can be used to display images from CD or DVD media. Most of the newer "syngo"-speaking devices and workstations are equipped with software to burn a Syngo fastView together with clinical images on CD or DVD. These images can be viewed without the necessity of installing software.

Features of Syngo fastView can be found in (Kvet, 2013; Pianykh, 2008).

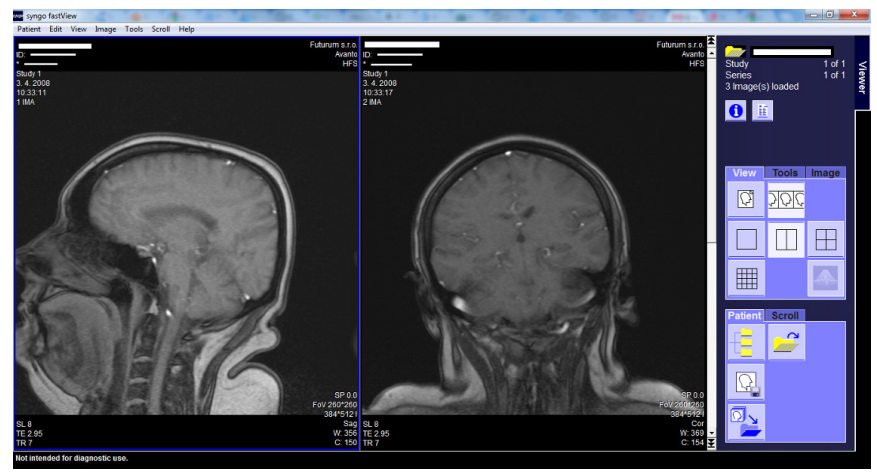

Figure 5. Syngo fastView

\section{Medical Analyses}

The project is medically oriented, creates a part of the information system for a hospital. It requires some insight into medical issues. To understand the principles of the application development, it is necessary to show basic overview of brain tumours and imaging methods used in diagnostics.

\section{Intracranial Tumours}

Intracranial tumours represent a diverse group of tumours that differ in localization, symptoms, histological composition. The occurrence of each species depends primarily on age. Impaired functions of the brain and brain nerves and even increased intracranial pressure are the most common symptoms of the brain tumour, in general. The most common symptoms are called paretic symptoms - limb movement disorder, numbness, vision, speech or mental changes. Another group of symptoms are the symptoms resulting from local brain tissue irritation manifested as different types of seizures. Syndrome of increased intracranial pressure is referred to a set of symptoms, which include mainly headache, vomiting and visual disturbances. (Nekula, 2005; Zeman, 2006). 


\section{Tumour Types}

Based on histology - tumours are divided into several groups - tumours based on brain cells, the brain nerves, tumours based on blood cells, and tumours that are metastatic to the brain, e.g. the spread of cancer cells blood riverbed from the primary tumour (mostly colon, lung, breast tumours). The difference between malignant and benign tumours has relatively less importance than in the tumours of other organs, because the brain is tightly enclosed in the skull and also slow-growing benign tumour can cause a serious problem. (Nekula, 2005; Zeman, 2006).

\section{Diagnostics}

Brain tumours are usually diagnosed after symptoms damaging brain functions. The basic diagnostic methods are:

- computed tomography (CT) based on the principle of X-rays

- magnetic resonance imaging (see below)

- positron emission tomography (PET) based on the principle of monitoring increased sugar metabolism by tumour cells

The other techniques are neurologic, ear, eye exams, blood tests, examination of cerebrospinal fluid and other specialized tests. Definitive diagnosis can be done by stereotactic neurosurgical techniques that allow sampling of the tumour using fine needle under CT guidance for the purpose of histological examination. (Nekula, 2005; Zeman, 2006).

\section{Magnetic Resonance Imaging (MRI)}

Magnetic resonance imaging is a diagnostic method used to create two-dimensional and three-dimensional images of organs in the human body. The method has been used in health care since 1980. It is unique technique, which is ncreasingly used mostly for its ability to create high-quality images without the use of radiation. Using this method, any structure of the human body can be processed and viewed, although other methods have failed to show it adequately. Technological advances in display quality bring continuous innovation, like accelerating disease diagnostic method (Kvet, 2012; Hornak, 2008).

\section{Principle of Magnetic Resonance Imaging}

Magnetic resonance imaging is based on the principle of measuring changes in the magnetic moments of nuclei of elements with odd atomic number placed in a strong static magnetic field after application of radiofrequency pulses. Due to the rotation of atom nuclei around axes (spin), the core magnetic field (magnetic moment) is formed. Hydrogen atom contains one proton in the nucleus and in the tissues as abundant. If the examined tissue is put in a strong magnetic field, layout proton spins are in one direction. In practice, there are two opposite directions, one of them predominates - so the resulting magnetic moment is therefore in one direction. In this state, the magnetic moment of protons has two types of movements - both rotate around axes (spin) while moving around an imaginary cone shell, which is called precession. If the radiofrequency pulse (electromagnetic waves in the radio short wave) is applied in the tissue with a frequency consistent with the proton precession frequency, resonance occurs according to the principle of magnetic moments deflection from the original direction by a certain angle and also synchronizes all proton precession. After the pulse occurs, everything returns to its original state. Time for that is known as relaxation time.

The time required to return biased magnetic moment is known as T1 relaxation time, "get out of sync" precession is known as T2 relaxation time. Both depend primarily on the composition of the material in the vicinity of protons. Signal, which is obtained after a series of different radio pulses, has the same character - it is electromagnetic wave that can be registered by receiving coils (basically antennas) and measuring size of the wave. A series of pulses required to obtain a measurable signal is referred as a sequence. Proton resonance frequency depends on the intensity of the external magnetic field. If this field gradient coils with appropriate modifications, we can obtain information about the location from which the signal arrives.

The principle of MRI is based on the measurement of magnetic moments of nuclei of hydrogen atoms in the water and fat.

During the patient scanning, image layers are made using various types of sequences informing about the difference of relaxation times $\mathrm{T} 1$ and $\mathrm{T} 2$ (T1 or T2-weighted sequence) or the number of protons (weighted sequence by proton density). It is necessary to compare the signal strength of the same place in different types of sequences to get the complete information. 
The examination takes 20-60 minutes demanding on the speed of particular device and the number of displayed sequences. (Kvet, 2012; Hornak, 2008).

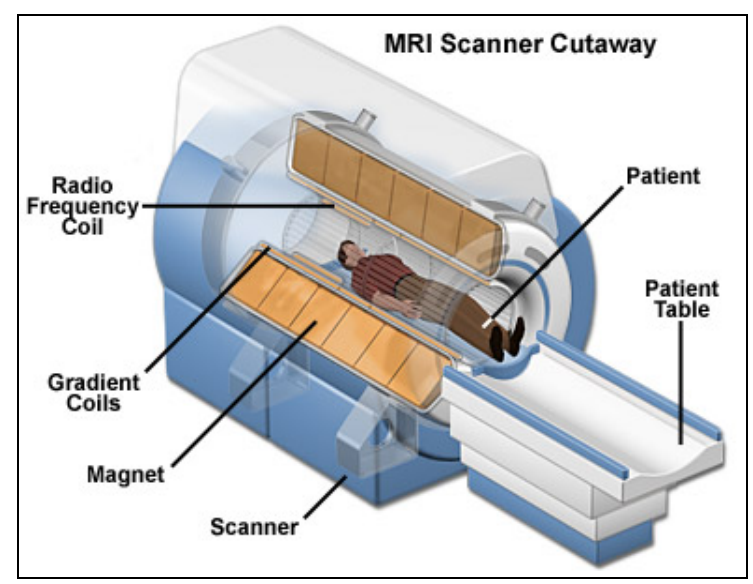

Figure 6. MRI scheme

(http://www.colinmenulty.com/blog/wp-content/uploads/2011/08/mri-scanner-cutaway.jpg [On-line 25.8.2013])

\section{The Use of MRI in Clinical Practice}

MRI is most often used in neuroradiology displaying diseases of the brain, spinal cord and spine. In addition, the usage of the diagnosis of musculoskeletal disorders cannot display all the components of bone and bone marrow by ligaments, tendons, muscles and cartilage to fluid. Increasingly, MRI is also used to view the organs in the abdomen, chest and neck. It is the most frequently used method for the detection or exclusion of focal changes or tumours. The advantage of MRI is based on the more detailed view of soft structures, the ability to view in any section plane, and the absence of ionizing radiation. MRI cannot be used in patients with pacemakers; or shift. (Zeman, 2006).

\section{MR Spectroscopy (MRS)}

Spectroscopy "in vitro" is based on observing the system from the outside environment, where the system is naturally present. It was used primarily before the appearance of magnetic resonance imaging. Now, the method "In vivo" is mainly used - system behavior in the environment in which it is naturally present - determining the chemical structure or the presence of certain substances in the focused area non-invasively. Despite of the great potential, it is used only in certain specific cases, because of the technical and time-consuming problems of the measurements; in addition, there is the need of really strong magnetic field. In the future, significant increase in use is expected. It is one of the few methods to track chemical processes and metabolism in normal tissues, as well as in pathological changed tissues.

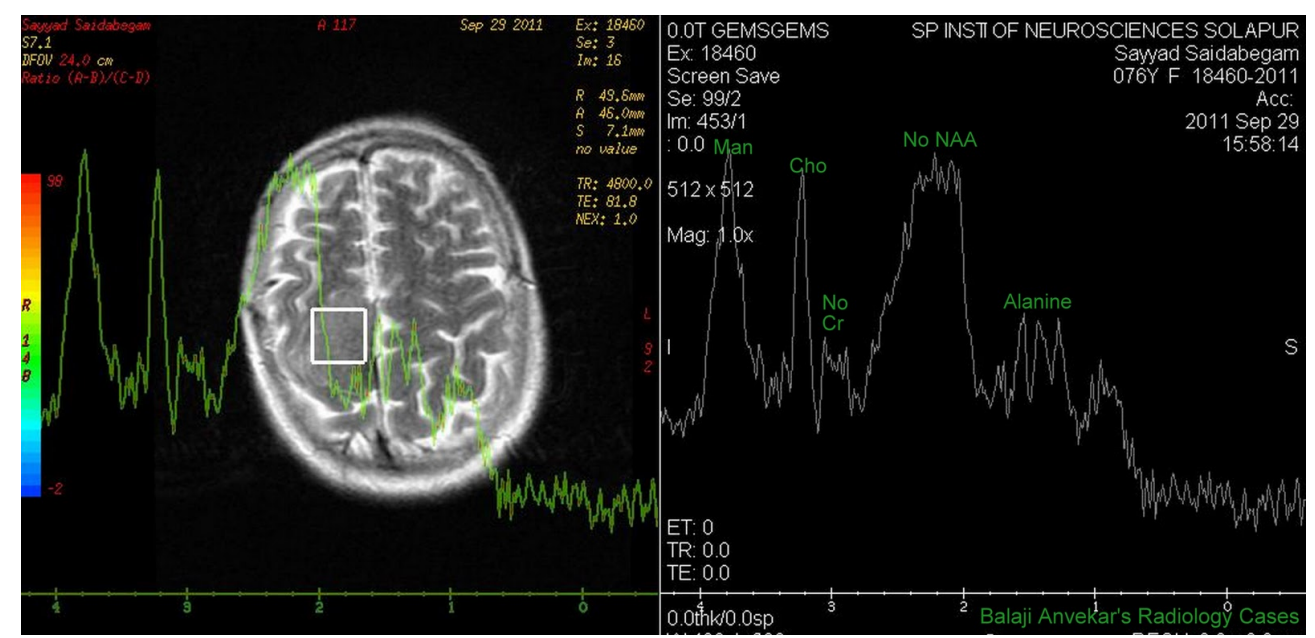

Figure 7. Meningioma processed by the MR spectroscopy 


\section{Tumour Markers}

Tumour marker is a substance, usually protein, the occurrence of which indicates the presence of the cancer. This substance can be almost exclusively produced by the tumour cells, thus the healthy cells do not contain them, but the markers can also be part of the normal cells, but in abnormal time or amount (presence during normal embryonic state is again appearing in adult tissue). Generally, we can observe the presence of these markers either within the tissue, which can distinguish normal tissue from morbidly amended, or in body fluids (e.g. serum, urine, cerebrospinal fluid). For our purposes, we use the term marker as a substance that is directly in the tumour tissue. Marker may be either protein, or cell surface proteins that are part of the cellular metabolism (such as enzymes, hormones). Special groups are markers produced by the collapse and necrosis of the tumour cells (e.g. fragments of cytoplasmic structures). Most tumours are characterized by the presence of one or several more or less specific markers. By processing the presence of multiple markers - although with a lower sensitivity and specificity - we get global information of the production of these substances to specific tumours.

Searching for cancer in the population to monitor the presence of markers in the blood is not used because of the relatively high sensitivity but lower specificity.

The importance of marker monitoring is essential for patients with proven presence of malignancy. At the time of diagnosis, it is important to know the values of the markers in blood and in the tumour tissue - to create the treatment protocol. Special presence of certain markers in blood or tissues are suggesting aggressive subspecies, the presence of other markers can be good prognostic sign.

Monitoring the presence of these markers is important in assessing the effect of treatment. Decreasing of the markers values indicates good treatment effect. If the values do not change or are rising, it indicates the resistance of the disease to a particular treatment. Monitoring the presence of markers is used after cancer treatment. If the values begin to rise, it means that the number of tumour cells in the body is again increasing, which means tumour reappearance or tumour in the form of metastases. Accordingly, it may proceed with treatment as soon as possible. (Kvet, 2012, 2013; Nekula, 2005)

\section{Implementation}

The main part of the whole application is the input file containing the values of the markers obtained by magnetic resonance imaging. The input file contains the identifier of the record, position of the measured voxel ( $\mathrm{x}, \mathrm{y}, \mathrm{z}$ axes), the marker values in the specified voxel and the measurement errors pertaining to a particular marker. Structure of this file may be characterized in three ways:

The first one is a CSV (Comma Separated Value) file. The structure looks like a classical table with 58 columns, 4 define the position, the rest (54 columns) contain the value of the marker and error got during the measurement of the marker. There is not necessary to get the all markers, if the type of the anomaly is specified, that's why some of them can be missing.

\begin{tabular}{|c|c|c|c|c|c|c|c|c|c|c|c|}
\hline ID & $y$ & $z$ & $z$ & Ala & Ala_SD & Cho & Cho_SD & $\mathrm{Cr}$ & $\mathrm{Cr}_{-} \mathrm{SD}$ & Gln & Gln_SD \\
\hline 0 & 0 & 0 & 0 & 44,6508 & 9,8641 & 84,9545 & 11,1195 & 10,3121 & 35,4200 & 91,3887 & 8,5895 \\
\hline 1 & 0 & 0 & 1 & 15,1078 & 32,4787 & 12,2794 & 20,9175 & 12,9528 & 37,7381 & 19,7908 & 4,2968 \\
\hline 2 & 0 & 0 & 2 & 33,5510 & 7,2037 & 41,5312 & 11,8363 & 85,8467 & 50,9073 & 3,0299 & 9,5060 \\
\hline 3 & 0 & 0 & 3 & 3,4207 & 12,3078 & 33,6234 & 4,1083 & 98,1959 & 11,4451 & 91,4263 & 6,8045 \\
\hline 4 & 0 & 0 & 4 & 43,9448 & 33,9521 & 89,9960 & 25,2200 & 72,1933 & 9,2013 & 20,0642 & 1,7917 \\
\hline 5 & 0 & 0 & 5 & 69,7599 & 19,4453 & 35,5144 & 2,9355 & 71,4408 & 49,0961 & 41,6109 & 2,6875 \\
\hline 6 & 0 & 0 & 6 & 65,0320 & 9,5264 & 66,7199 & 6,6280 & 29,8880 & 25,2115 & 93,0500 & 2,9753 \\
\hline 7 & 0 & 0 & 7 & 1,4384 & 16,5044 & 93,9893 & 7,2396 & 1,5230 & 14,5102 & 81,7068 & 12,0204 \\
\hline 8 & 0 & 0 & 8 & 20,4445 & 44,6979 & 12,2822 & 32,6038 & 7,0209 & 23,2898 & 32,3844 & 4,2939 \\
\hline 9 & 0 & 0 & 9 & 20,0698 & 35,1697 & 42,3146 & 37,8528 & 42,4324 & 43,6387 & 65,4374 & 6,7000 \\
\hline 10 & 0 & 1 & 0 & 12,8794 & 24,9478 & 60,4904 & 18,3295 & 65,9901 & 5,8907 & 93,4894 & 10,3847 \\
\hline 11 & 0 & 1 & 1 & 56,7193 & 36,6331 & 94,6579 & 27,8126 & 3,0722 & 11,9777 & 79,4823 & 8,9108 \\
\hline 12 & 0 & 1 & 2 & 22,2727 & 49,8133 & 61,2960 & 14,1833 & 4,2136 & 1,7670 & 0,1328 & 4,2313 \\
\hline
\end{tabular}

Figure 8. Input CSV file

The second way is based on the use of XML structure (the left part of the Figure 9). The results of pre-processing tool LCModel are saved in this format, our application only takes, evaluates, processes them.

The last type of input file is a temporal database. It is a good way for the MRI results during the treatment of the patient. It has been developed by us and provides a lot of advantages like possibility of direct access to any state in the past, evaluation of treatment effects, prognoses creating and so on. In addition, the temporal system in comparison with other types, stores only markers values, which change during the time, is greater than the 
defined $\varepsilon$. It radically saves the storage capacity without the loss of the precision. Values are of course saved after processing and therefore the later work with them is easier and faster. The main difference between the database and other streams is the time management. The temporal database contains the whole measurement results of the patient during the time - from the time of getting diagnosis, whereas the streams contain only one set of the results and when processing time difference and treatment reactions, the material must be processed separately. The complete structure and methods for managing temporal database can be found in (Kvet, 2013; Jähne, 2002).
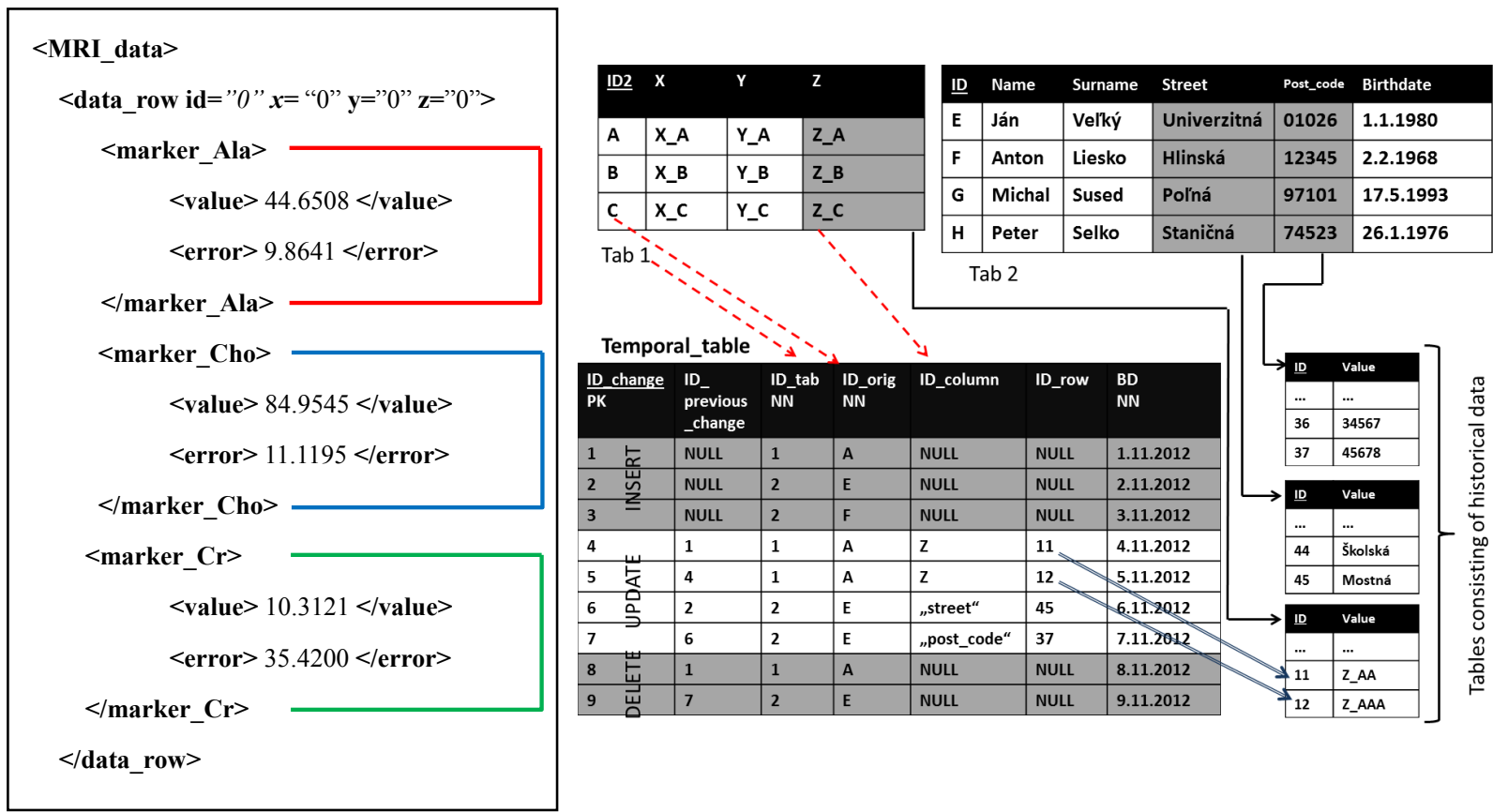

Figure 9. XML file and structure of temporal database

The application in standard mode works with two markers simultaneously. One of them (mostly choline) is fixly defined and the other is selected primarily on the basis of the type and characteristics of tumor tissue anomalies. Individual markers can be combined each to create new markers based on the relatively low sensitivity and specificity of some markers. Composing such markers can create a new marker, which more detail describes the character and properties of the tissue. The Figure 10 shows the screenshot of the "New marker" module. The list in the left part contains all existing markers, even user defined and the calculator for the basic marker combining. The right part contains the definition of the error processing. Now, we are developing more sophisticated tool for new marker definition processing, which will allow creating markers based on conditions, functions, thresholds and so on. It will be also able to approximate the function based on the input values - to create the function for the new marker definition automatically. Using neural network and special functions and databases, we want to create and show the relationships and correlation between the markers based on the specific tumour type. 


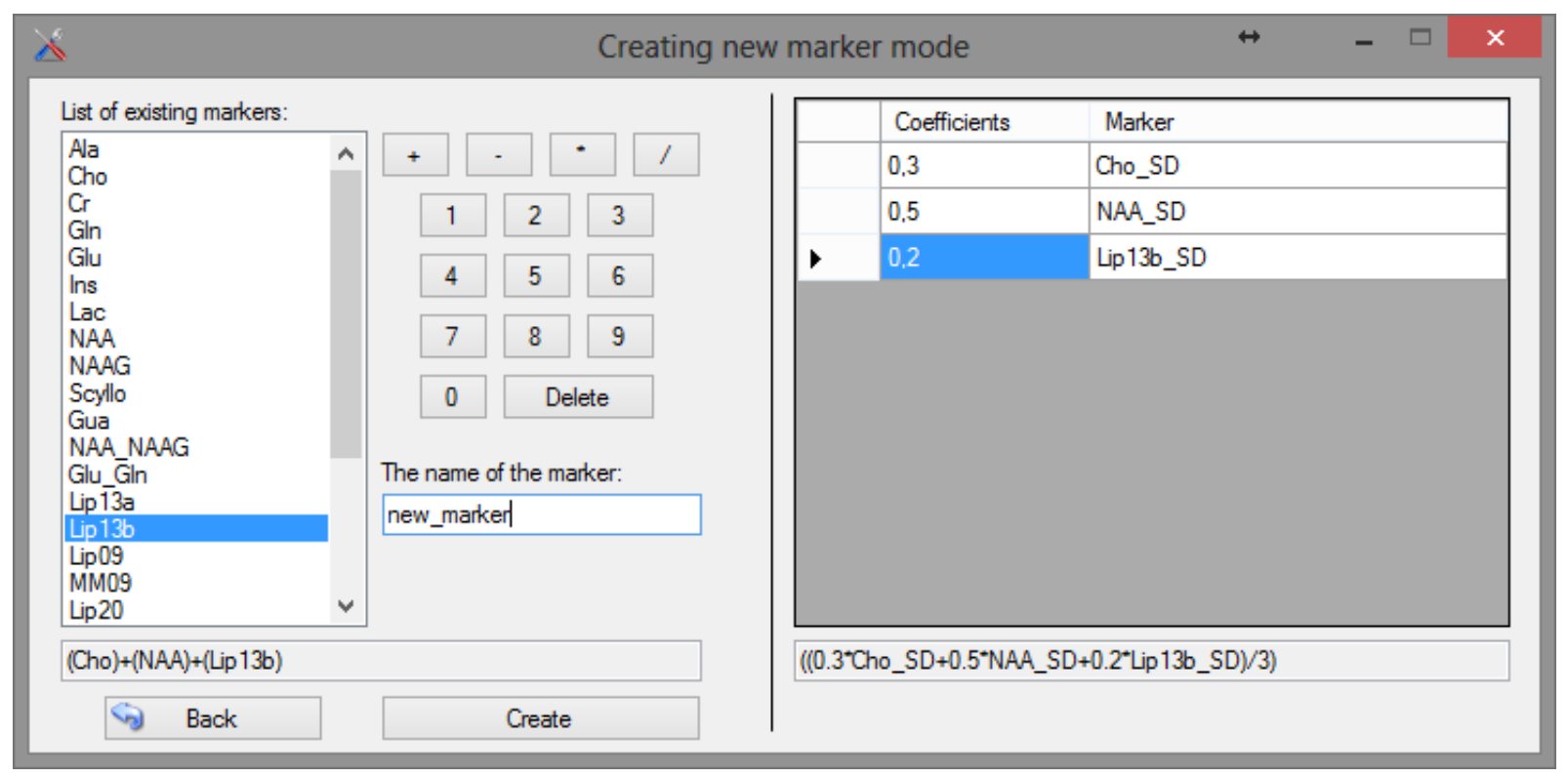

Figure 10. Module for creating new markers

The new value of the marker, which is created using the combination of the other markers is expressed in Equation 1 - set $M$ contains all the markers in the definition (not only standard, but also created ones, the definition must contain at least 1 marker), $w_{m}$ is the weight of the marker definition, $c$ is a constant added to the definition (a definition that does not have to include a constant of course).

$$
\left(\sum_{m \in M} w_{m} * m\right)+c=n e w \text { marker }
$$

The error value is calculated by a weighted average of the markers:

$$
\frac{\left(\sum_{m \in M} w_{m} * m\right)}{|M|}=\text { error }
$$

Access to the CSV or XML file is also provided by the database commands. Temporal database as input is mostly used for showing the progress of the disease, but it can be also used for only one snapshot of the time processing and visualizing. Before the loading, we need to get complete the definition of the marker, not only its name, because it could be a marker that is not standard, but user-defined and thus its value is not set directly. Input data are normalized to get the range from the interval $\langle 0 ; 1\rangle$. When manipulating with the user defined marker, it can happen that the values are lower then " 0 ", which means, that the range must be shifted into the positive range by adding the constant to each value and then, the normalization can be provided (Kvet, 2012, 2013).

Methods for carrying out standardization of values:

- Maximum normalization.

- Range normalization.

After successful loading input data, the main window is shown. It contains the information about the patient, settings of the application like marker names, threshold, maximal value of error and so on. The importance of these values will be described later.

The Figure 11 shows the main window of the application. The table inside the window is shows the values of the selected marker (the first marker) highlighted in color based on the category of the value with the indication, whether the anomaly is found or not. If so, there is also information about its localization. Then, the real model of the head, respectively brain, can be shown and these values are directly correlated with the two or three dimensional models. 


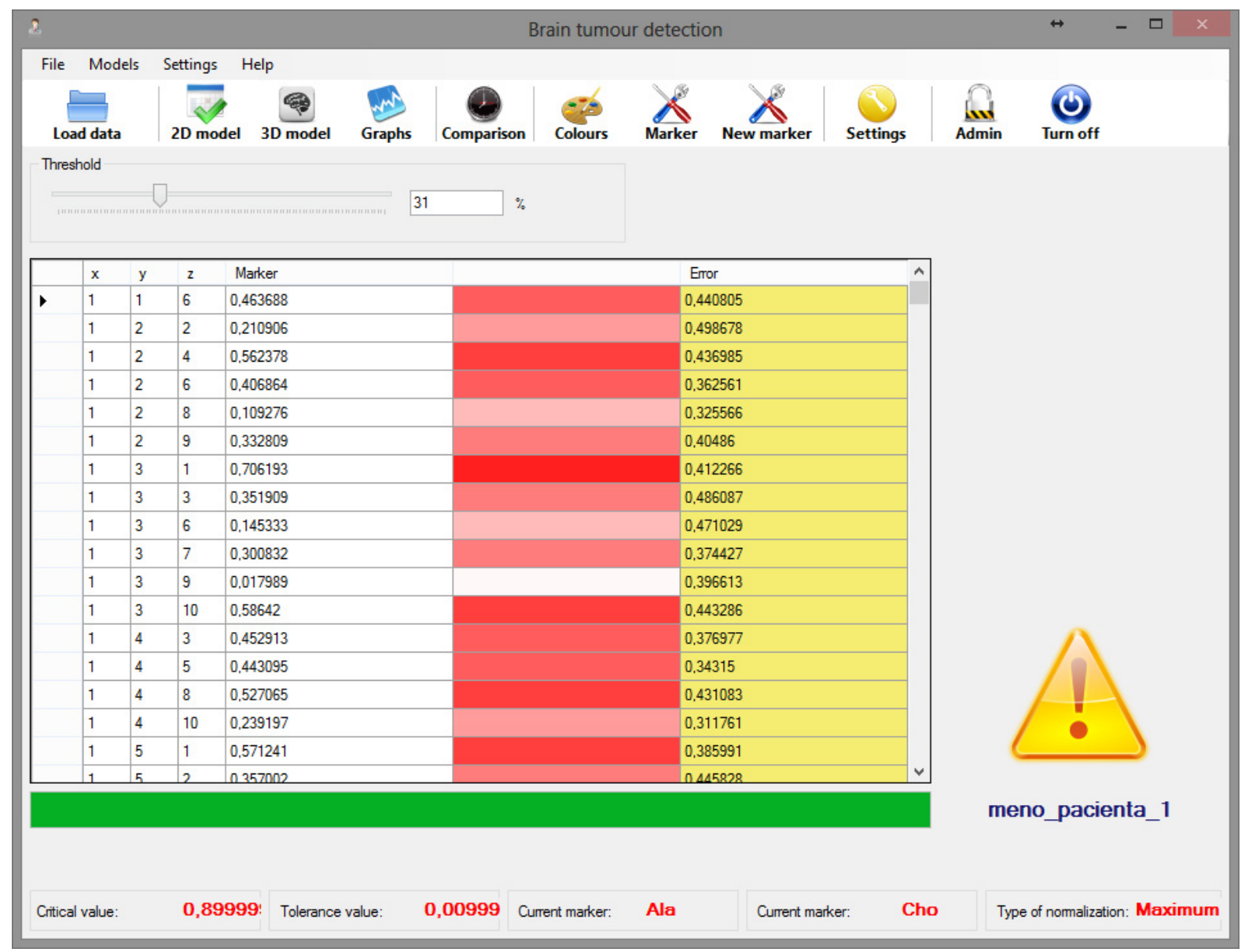

Figure 11. Main window of the application

Special case is shown in Figure 11, where we can see the exclamation mark in the right part. It means that, although the data have been loaded and processed, the system cannot directly detect whether there is the area with the anomaly with potential risk of a tumour or not. This situation is caused by the poor quality of the results, or measurement with great precision errors. In this case, there are two opportunities. The first one is to let the system work with the other markers or their combination, which can mostly solve the problem successfully. The second approach is based on approximation of the incorrect measured values. The system offers wide range of methods to get more reliable valus with the significantly lower measurement error. One of them - the easiest is described in the section 15. If the input data contains too many incorrectly measured values - noise, it is necessary to make a new measurement, because this is not applicable. In this case, even an experienced doctor would not be able to identify potential risks.

\section{Models}

The problem of the above-mentioned commercial applications is the inability to process the results in time to monitor the progress of the tumour. Another disadvantage is that values of the markers are not displayed, as well as lack the three-dimensional visualization of values of markers in the brain.

Our developed application allows wide range of models and offers a lot of information to simplify processing. The models offered in our application:

\subsection{Graphs}

Graphs module after selecting two axes sections depicts the value of the third axis in the form of a graph. The values of the currently set two markers with error values less than the selected threshold are shown. The principle of reduction of measurement error and calculation of the replaced value is described later. A common requirement is to compare the values of these two markers in every place. Therefore, it is possible to portray the two graphs together and see the values of both in one place. 

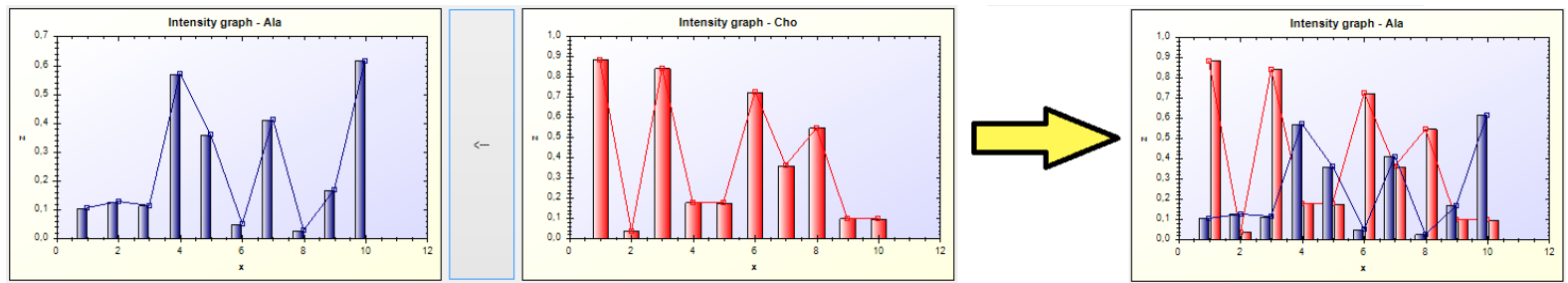

Figure 12. Graphs

For the purpose of graphs, the graphic ZedGraph is used and it offers all needed types of interactive graphs.

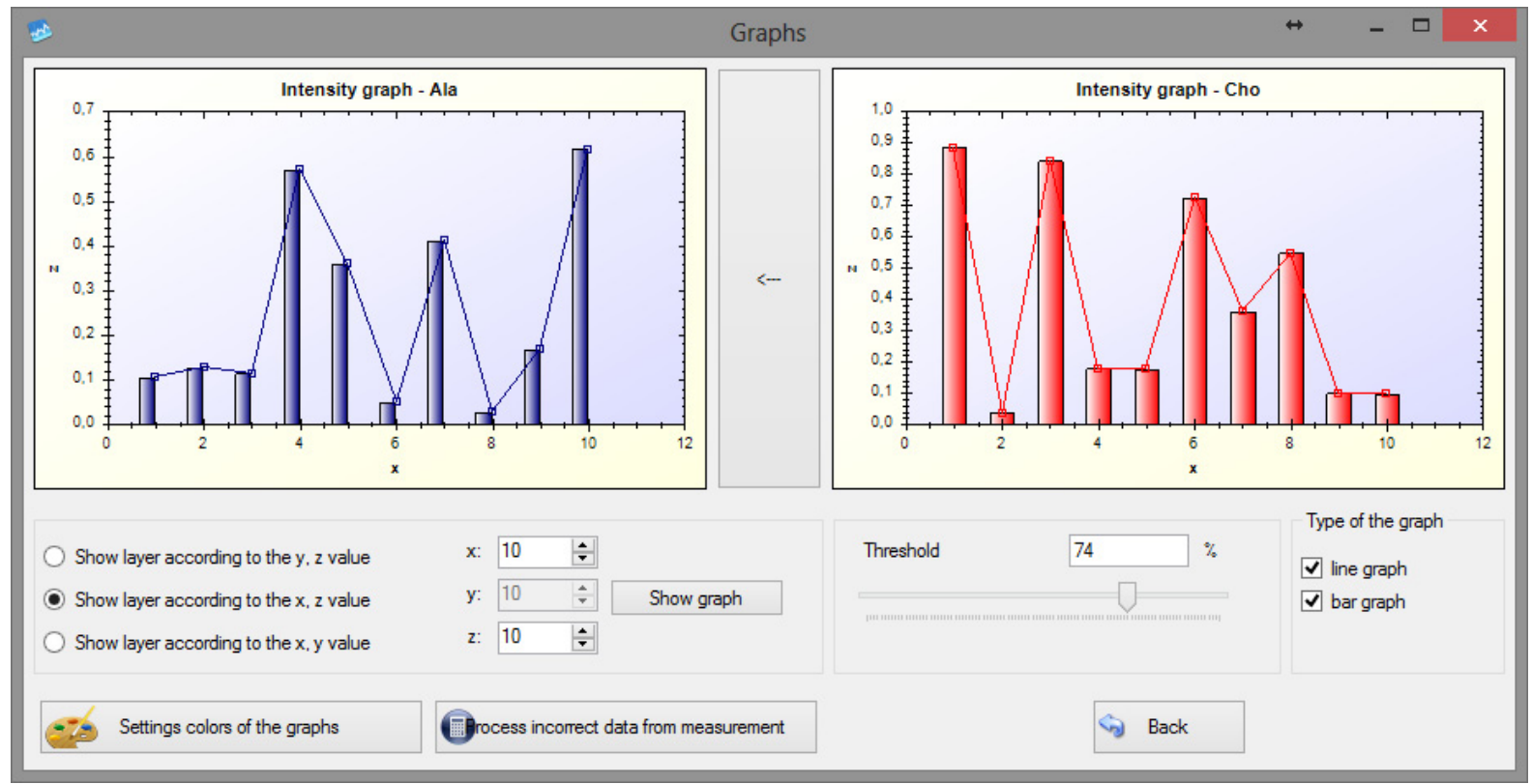

Figure 13. Graphs module

\subsection{Two-Dimensional Model}

2D model section consists of four basic display parts important for user consideration:

- Values of the first marker in the selected two-dimensional slice with the appropriate values of the error of the measurement in that location.

- Values of the second marker in the selected two-dimensional slice with the appropriate values of the error of the measurement in that location. This marker is mostly choline, but can be changed in the admin settings interface.

All these data are projected in thespecific datagrids and are colourly displayed based on the values. The rate of the colour differences between the intervals and categories can be set in the "Colour module", where the number and borders of the intervals are chosen. The default setting is a spectrum of colours from white to red for marker values and a range from the green to red for measurement error influenced by the circumnstances and also by the used MRI device - Figure 14. 

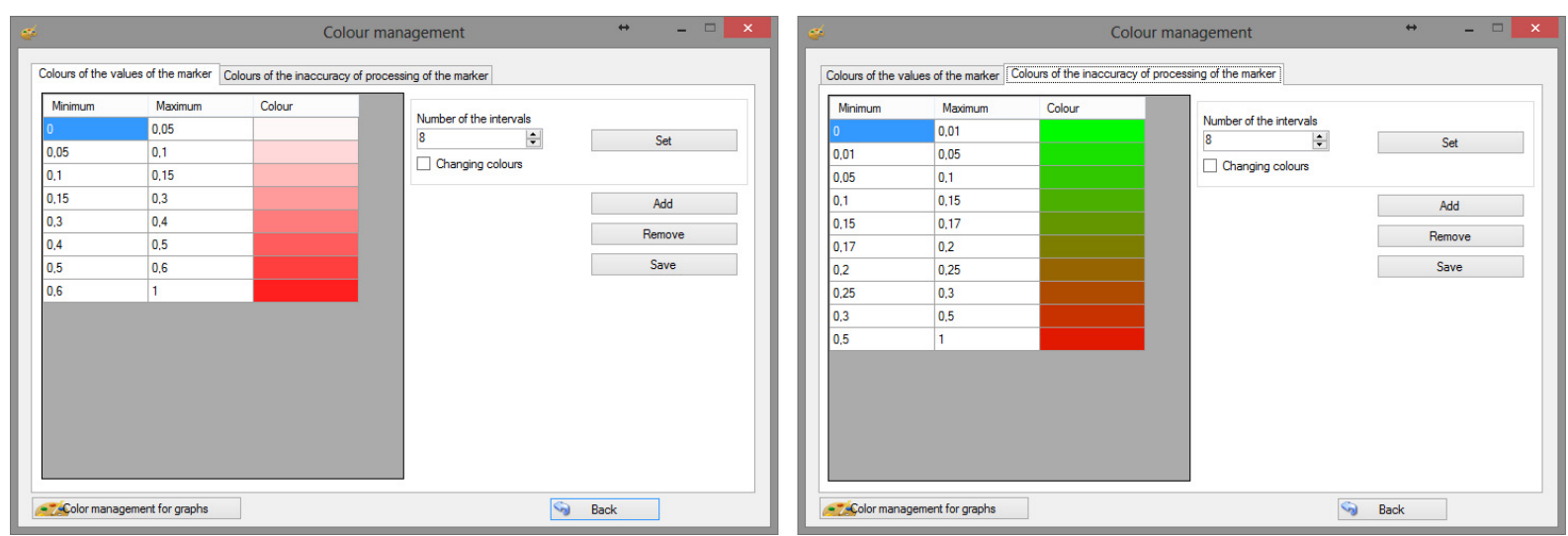

Figure 14. Color spectrum

There are two possibilities, how to perceive the error of the measurement reflected to the values of the markers in the datagrids. The difference is in the method, which displays the values. If the value of the measurement error at a given voxel exceeds the maximal limit, we accept, the shown value can be blue indicating the potencially incorrectly measured value or the original value obtained on the basis of color intervals can be shown. In this case, we do not consider the data processing to reduce measurement error. If we need to reduce the value of the measurement error, the module for error processing is used - the principles are described in the Section 15. The display mode can be directly linked to the acquired images (DICOM data) got during the CAT scan to create interactive way of evaluating and displaying the anomalies - Figure 15. The complete module for two dimensional visualization is shown in the Figure 16.

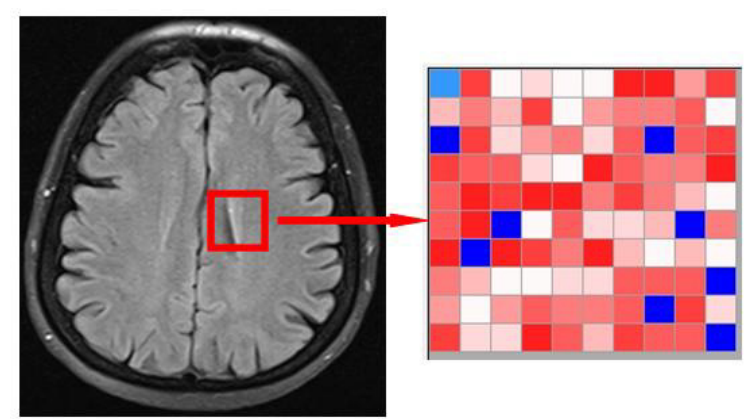

Figure 15. 2D model and the slice of the brain

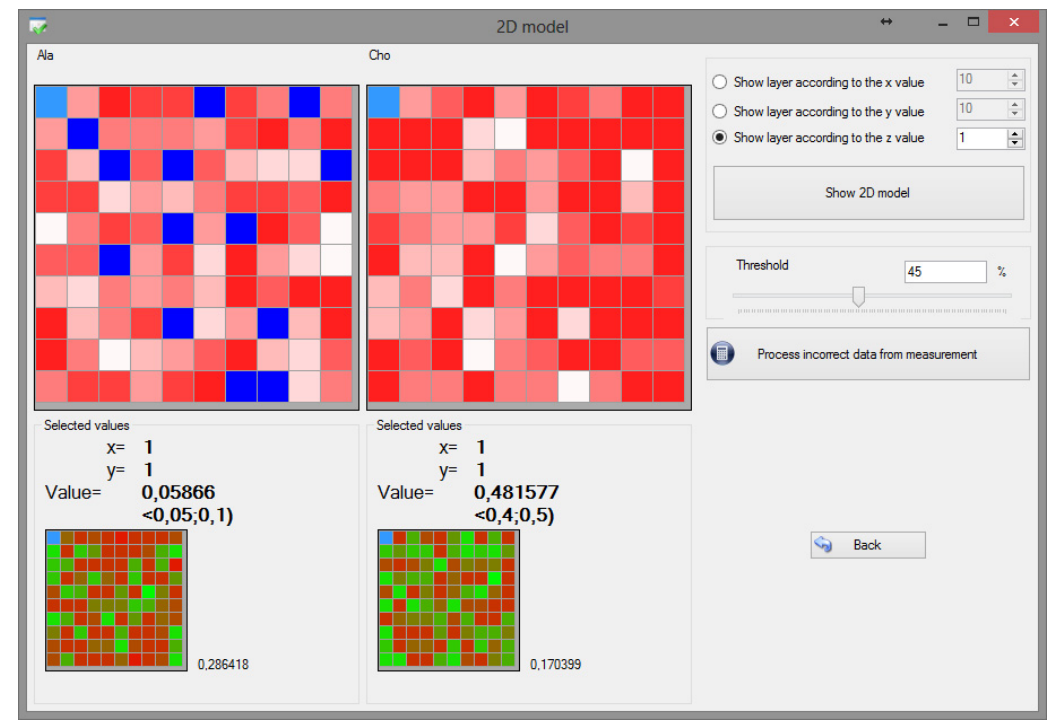

Figure 16. Two dimensional data module 
The selected position in the grid is shown after clicking on any cell (blue arrow in the Figure 17). At the same time, the user gets the information about the value of the selected marker at that position (orange arrow in the Figure 17), inclusion to the interval (green arrow in the Figure 17) and also the value of the error (gray arrow in the Figure 17). If the marker value is higher than the limit (critical value), exclamation mark is shown representing the location with extremely high value of the marker.

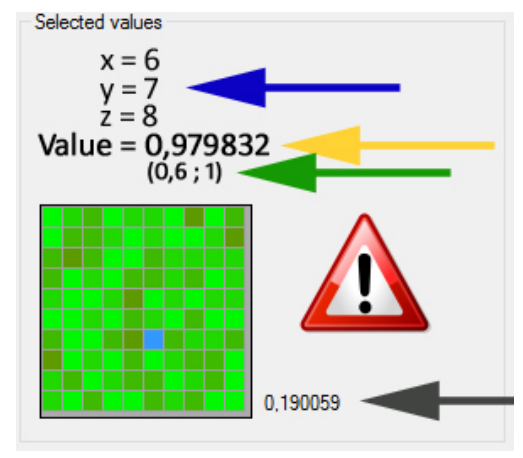

Figure 17. Marker values

\subsection{Three-Dimensional Model}

Another type of the results presentation is the three-dimensional model, which links all the two-dimensional models together. Each layer can be considered as a slice of a cuboid. The sections and slices are defined by the user to see all the anomalies with their location colourly displayed. After connecting these layers with the image of the patient's brain, we can get the complex information about the characteristics, properties and position of the anomaly directly in the brain structure. The model can be also rotated and zoomed. It is based on the library "XNA Game Studio 4.0 Refresh", which was primarily developed for the games, but can be also used in the medicine applications. It is based on the hardware acceleration, speed and stability and allows integration with any modern technology. For rendering one surface, four vertices and six indices are used. The whole system of the texture rendering is based on the triangles. Six of these indices determine the vertices of the two connected triangels forming the rectangle. The Figure 18 shows the principle of the rendering contours of the trianges (left part of the figure) and the complete model on the right part. The complex principle of modelling is detailly described in (Kvet, 2013; James, 2010).

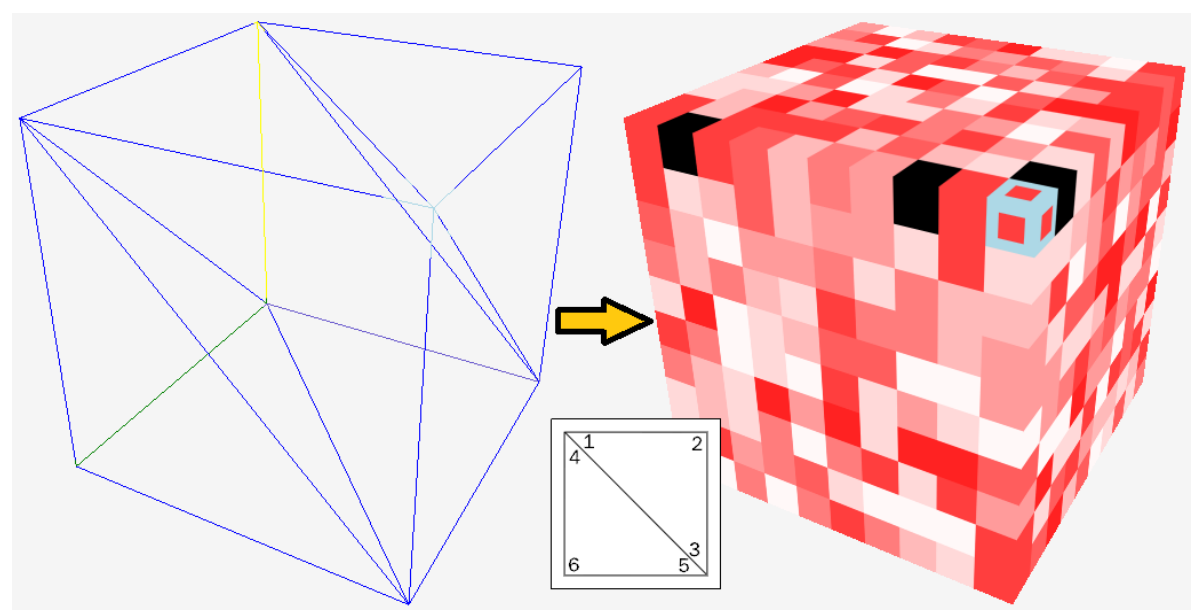

Figure 18. LineStrip and TriangleList (Mešina, 2012)

The next figure shows the whole model connected to DICOM data. 


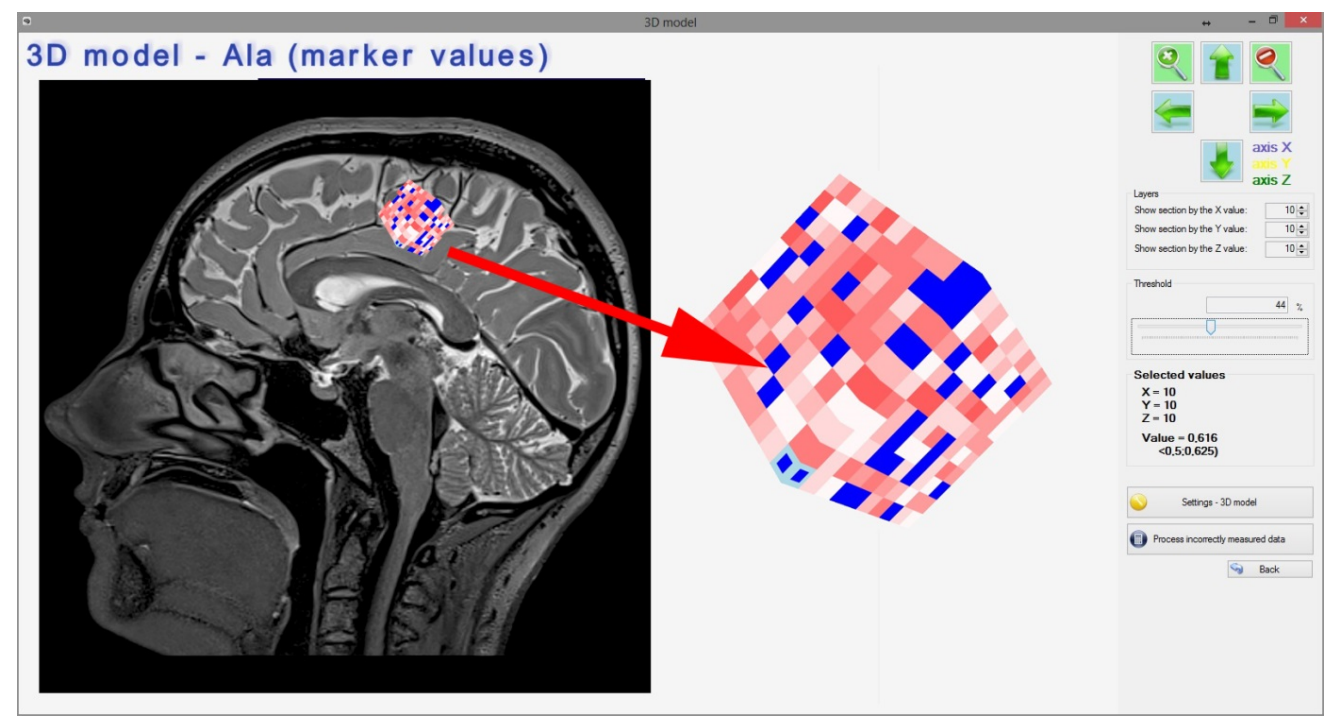

Figure 19. DICOM data and 3D model (Mešina, 2012)

\section{Settings and Parameters}

Most important parameters and attributes of the application are:

Critical value - expresses the maximual value of the marker, which is still considered to be acceptable and is not considered as a potential anomaly.

Tolerance value - expresses the maximal acceptable difference between the different results of the CAT scan over the time. This value is used to monitor tumor growth (e.g. a comparison before and after the surgery).

Threshold value - expresses the maximal value of measurement error, which is still accepted by the user. If they want to reduce the value of the error, it can calculate the new value of the error marker and surroundings.

\begin{tabular}{|c|c|c|c|c|c|c|}
\hline \multirow[t]{2}{*}{ Current marker: } & Ala & & Current marker: & Cho & & Type of nomalization: Maximum \\
\hline & & Critical value: & 0,9 & & Tolerance value: & 0,01 \\
\hline
\end{tabular}

Figure 20. Actual application setttings

Attributes brain_cur_marker, brain_cur_cholin store values of the selected marker and standard marker (mostly choline) throughout the measured spectrum (head, brain). For each of these attributes, there is the same size and structure - data of the measurement error in that location. The number of the slices in fact represents the quality of the measured data, the quality of the MRI device, simply the resolution of the device. It can be set manually or the system can automatically set the appropriate values based on data to be loaded.

Measured values have often (especially at the edges of the investigation) high measurement error and therefore it is possible and even necessary to replace them with new values, calculated from the neighborhood, based on specific properties, diffusion and other parameters. If the value is changed, this information is also stored (red arrow in the Figure 21).

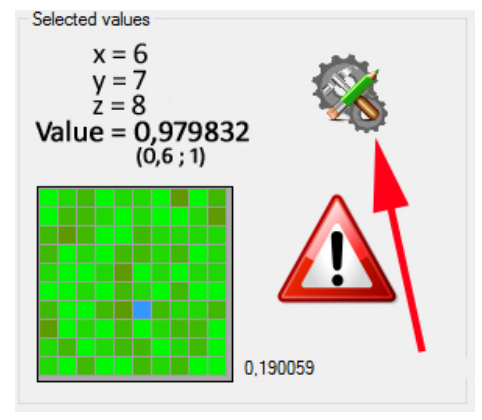

Figure 21. Processed data 


\section{Error processing}

The data obtained from the magnetic resonance imaging examination of the patient may not have the required quality at each voxel. Even, in some locations, the marker value can be even undefined - that location was not measured at all or with the poor quality.

\subsection{Decreasing the Level of the Error Processing}

Loaded data must be "cleaned" to show relevant data and to locate the anomaly, although there is no potrencially risk area. Vice versa, there can be also the other problem, that the data do not directly locate the anomaly or the tumour, although there is a problem. The user sets the threshold value, which indicated the maximal error (in percentage), which is accepted. All the values with the error exceeding the limit cannot be considered relevant. Buf if the doctor needs to get the values also in those unmeasured aread, our application offers the possibility of new values of the elements calculating. There are a lot of sophisticated methods to do this based on conditions, thresholds, relationships between the markers and so on. The easiest way of processing is to replace the value based on the surroundings (Figure 22). When we realize the fact of the diffusion, the method is suitable for easy problem management.

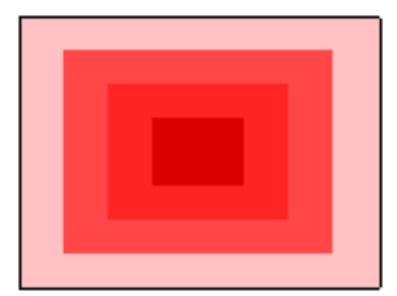

Figure 22. Surrounding cells

Thus, each element has 26 elements (or less) with a width $=1$. The new value of the element is created by summing the values of all surrounded elements (specified by the width) and divided by the number of these elements. The new value of the element is considered correct only if the value of the error is reduced (value of the error is calculated the same way as the new value of the element). There is important to emphasize that it is not necessary to reduce the error value below the threshold. The main point is that the error value is diminished. Following formula refers to the way of calculating the new value of voxels, sets A, B, C define the elements in the axes.

$$
x_{i j k}=\frac{\left(\sum_{a=-1}^{1} \sum_{b=-1}^{1} \sum_{c=-1}^{1} x_{(i+a)(j+b)(k+c)}\right)-x_{i j k}}{|A|^{*}|B|^{*}|C|-1} \quad \exists x_{(i+a)(j+b)(k+c)}
$$

If the new value is defined by the wider surroundings, weights of the value elements are added to the formula (the closer element has the higher weight). $\mathrm{w}_{(\mathrm{i}+\mathrm{a})(\mathrm{j}+\mathrm{b})(\mathrm{k}+\mathrm{c})}$ expresses the weight of the element $x_{(i+a)(j+b)(k+c)}$ - the value of the element at the position $(i+a)(j+b)(a+c)$. (The weight of the element $x_{x j k}$ is "0", because it is considered to be untrustworthy).

$$
\mathrm{x}_{\mathrm{ijk}}=\frac{\sum_{\mathrm{a} \in \mathrm{A}} \sum_{b \in B} \sum_{\mathrm{c} \in \mathrm{C}} \mathrm{x}_{(\mathrm{i}+\mathrm{a})(\mathrm{j}+\mathrm{b})(\mathrm{k}+\mathrm{c})} * \mathrm{w}_{(\mathrm{i}+\mathrm{a})(\mathrm{j}+\mathrm{b})(\mathrm{k}+\mathrm{c})}}{|\mathrm{A}|^{*}|\mathrm{~B}|^{*}|\mathrm{C}|} \quad \exists \mathrm{x}_{(\mathrm{i}+\mathrm{a})(\mathrm{j}+\mathrm{b})(\mathrm{k}+\mathrm{c})}
$$

However, the diffusion does not model the values very well and in this field, it can be really dangerous to replace the value, which is not $100 \%$ correct. The problem is just not completely uniform diffusion due to different structure and properties, that's why the proposed method is good, but must be corrected after the processing using the other specific methods. The problem is described in the next figure. The left part shows the real image of the brain slice, the image in the middle shows the result after the linear approximation. The last one is more relevant, uses wide range of centres of the approximation. It also considers the relationships between the other markers. The correctness of these developed supporting techniques is about $80 \%$ and these techniques are still improved and new ones are developed (Kvet, 2012, 2013). 

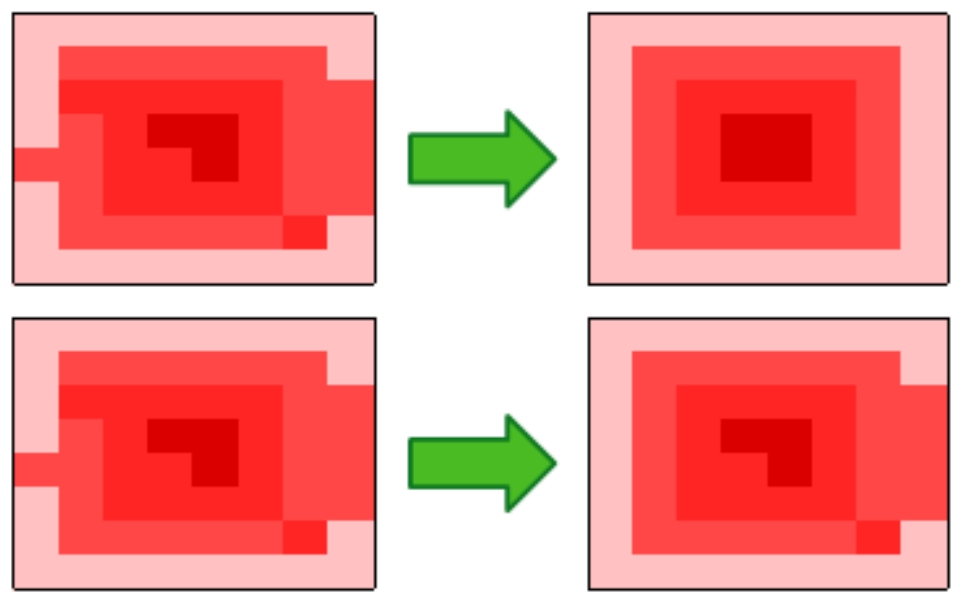

Figure 23. Real and processed image

Elements for processing can be selected manually from a table (datagrid), or all the elements according to the criteria are selected., The following figure shows the unprocessed data element - its position (position $\mathrm{x}, \mathrm{y}, \mathrm{z}$ ), the current value and the error value with the corresponding color category:

\begin{tabular}{l|l|l|l|l|}
\hline$x$ & $y$ & $z$ & Value & 0,286 \\
\hline 1 & 1 & 1 & 0,059 & 0,293 \\
\hline 1 & 1 & 5 & 0,012 & 0,441 \\
\hline 1 & 1 & 6 & 0.464 & 0,272 \\
\hline 1 & 1 & 9 & 0,602 & 0,299 \\
\hline 1 & 1 & 10 & 0,338 & 0,249 \\
\hline 1 & 2 & 1 & 0,249 & 0,499 \\
\hline 1 & 2 & 2 & 0,211 & 0.437 \\
\hline
\end{tabular}

Figure 24. Voxels before the processing (Kvet, 2012)

After successful processing (successful processing means a reduction of the error value), the new values and info about processing are displayed:

\begin{tabular}{|c|c|c|c|c|c|c|}
\hline$x$ & $y$ & $z$ & $\begin{array}{l}\text { Value before } \\
\text { processing }\end{array}$ & $\begin{array}{l}\text { Value after } \\
\text { processing }\end{array}$ & $\begin{array}{l}\text { Error value before } \\
\text { processing }\end{array}$ & $\begin{array}{l}\text { Enror value after } \\
\text { processing }\end{array}$ \\
\hline 10 & 10 & 10 & 0.616 & 0,267 & 0,481 & 0.191 \\
\hline 10 & 10 & 8 & 0,241 & 0,255 & 0,311 & 0,226 \\
\hline 10 & 10 & 5 & 0,371 & 0,407 & 0,329 & 0,224 \\
\hline 10 & 10 & 4 & 0,586 & 0,317 & 0,47 & 0,228 \\
\hline 10 & 10 & 3 & 0,571 & 0,24 & 0,319 & 0,308 \\
\hline 10 & 10 & 2 & 0,279 & 0,204 & 0,484 & 0,332 \\
\hline 10 & 10 & 1 & 0,192 & 0,196 & 0,461 & 0,328 \\
\hline
\end{tabular}

Figure 25. Voxels after the processing (Kvet, 2012)

The Figure 26 shows the entire form for processing data errors of the measurement, the elements that have not been processed yet and also elements which error has been reduced. The right side constains the navigation for threshold and sections setting. If it is necessary to see the original values, this option is also available. The methods for the data processing are usually selected automatically, but the process can be modified in the admin form, which is, however, password protected using MD5 encryption. 


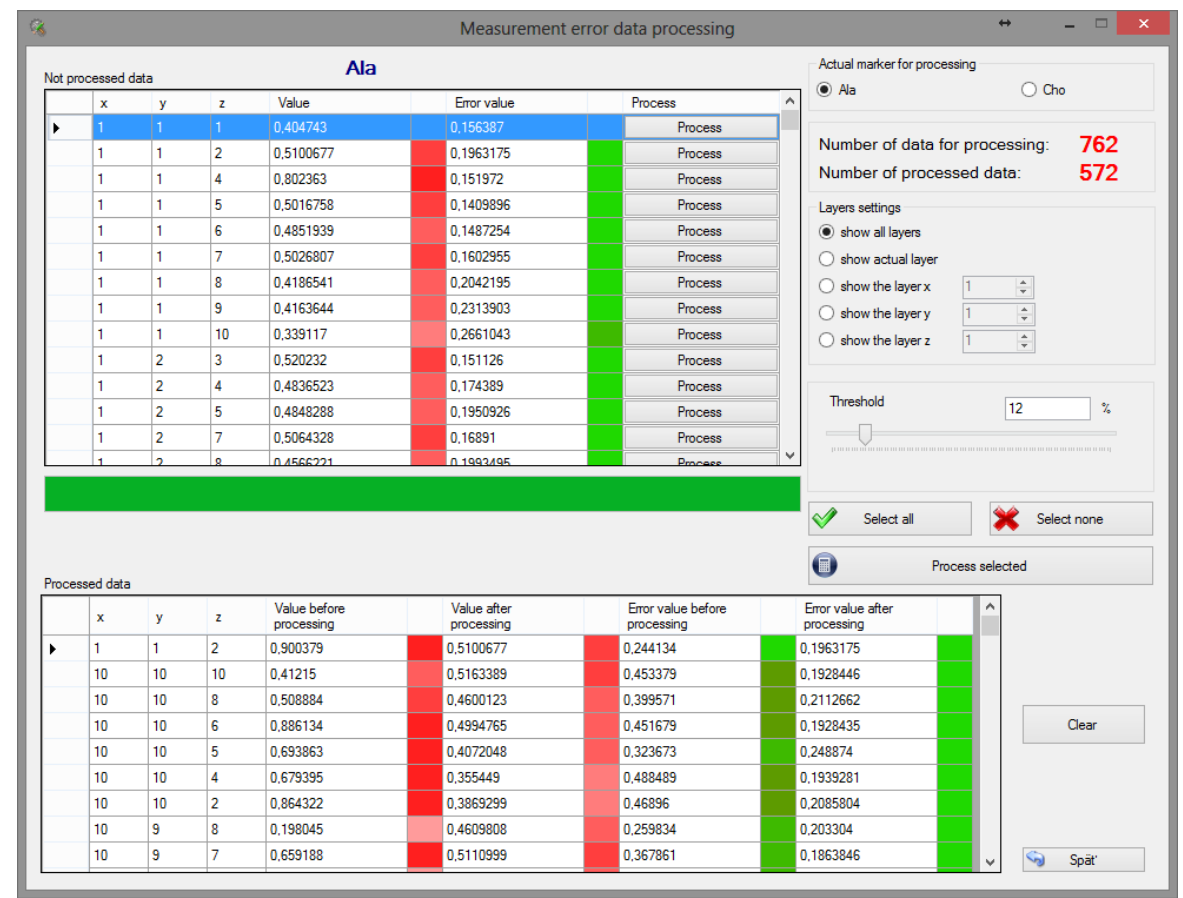

Figure 26. Error data processing module

\subsection{Noise Reduction}

A limitation of a previous described system is the noise detection problem. The value of the measurement error does not accurately characterize the measured value. Therefore, it is necessary to detect and remove noise from the data.

In principle, the noise can be divided into 2 categories - neighbourhood noise and noise in slice (Figure 27). Slice noise is just detectable and can be removed by neighborhood, where individual values can be approximated. However, if the data have the neighbourhood noise, this can not be processed without in-depth treatment of other markers and their combinations. If the system does not have required markers result, we can replace them with the older patient results (if available), otherwise we cannot handle the problem at all.

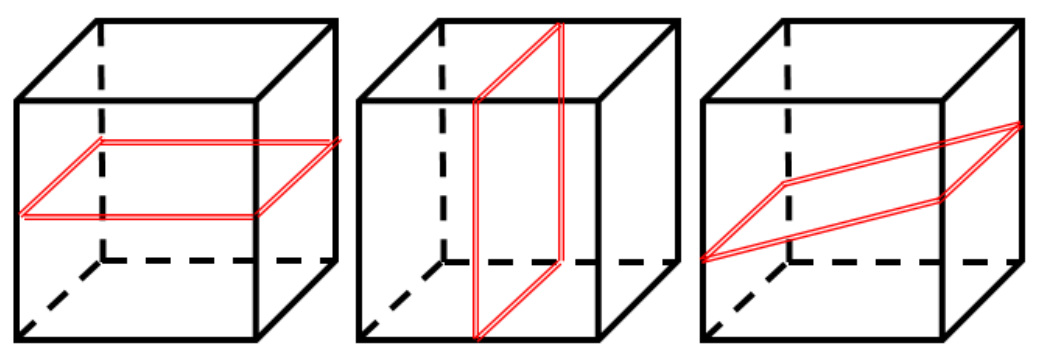

Figure 27. Principle of slice noise

Other major complications include the issue of proper system rotation - the measured system may be measured twisted, not strictly horizontal and vertical (Figure 28), so it must be properly rotated and any missing values should be approximated, if necessary. 


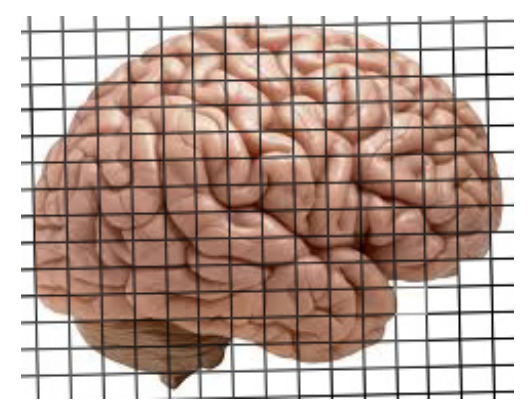

Figure 28. Measurement calibration problem

\section{Comparison in Time Progress (Temporal Database)}

Tumor progression monitoring in time, as well as the reaction of the body and the tumour tissue to the treatment is a basic requirement. As already mentioned in the introduction, there are two possibilities for loading data, either the results of each examination are stored separately (CSV, XML) or all the results of the patient are stored together, in our case, it is a temporal database. If the patient is examined, their results can be added to this database to enable track the progress over time. Either all the measured data can be stored, or only only those, that are in specified location, or only the values, the diference between actual and historical data exceeds the value $\varepsilon$. Doctor can compare these values of the marker to see the progress colourly displayed and rated.

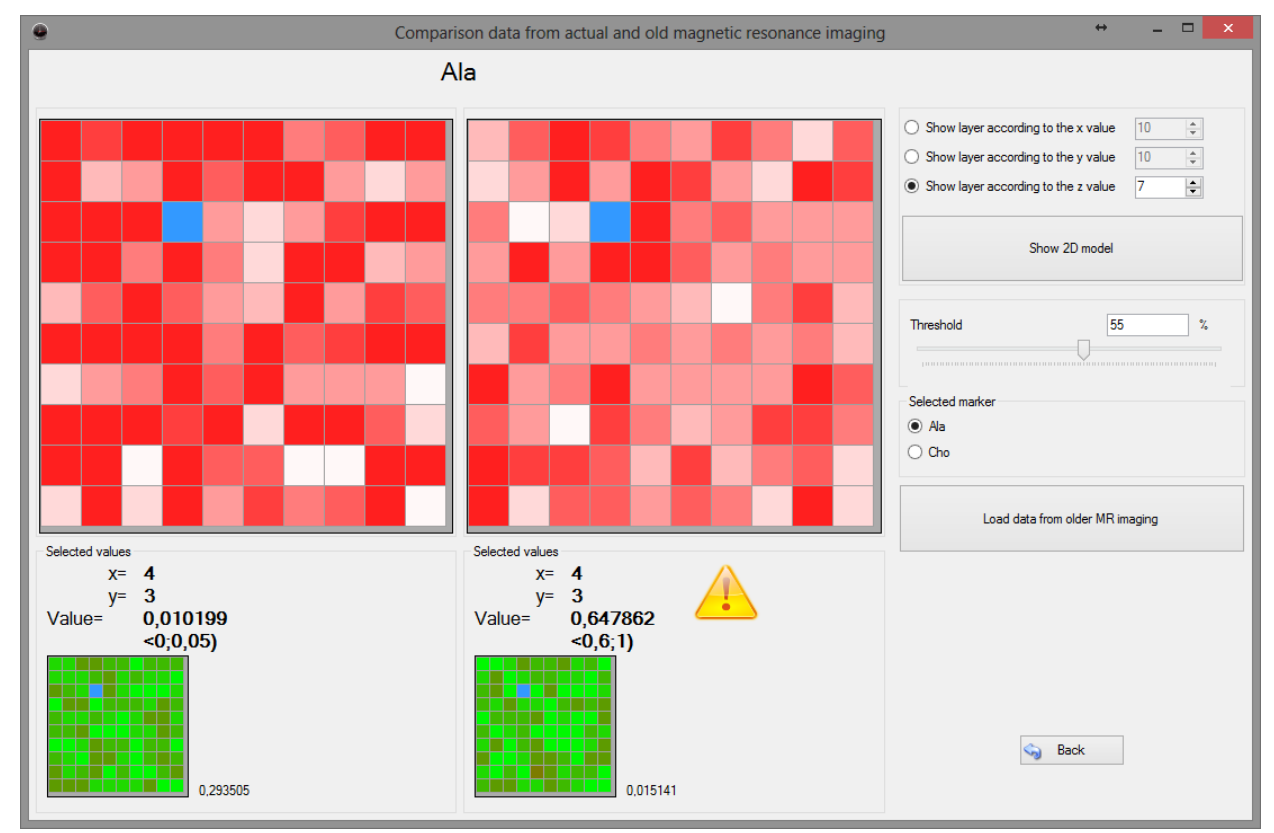

Figure 29. Comparison data from actual and old magnetic resonance imaging results (Kvet, 2013)

\section{Support Database}

The aim is to create complex database containing tumor types, characteristics of the patients and the reactions to the treatment with the results of the magnetic resonance imaging. This would help the doctors to update the profile treatment based on the historical treatments of the patients. It could also improve and simplify decision making process. Later, it could be interesting to compare the results and look for the dependence between the the factors - the type, location and histological composition of the tumor, the patient's age, general condition and his associates diseases, the treatment options and so on.

\section{Results}

The result of the presentation is medically oriented application aimed on displaying and processing the results of an MRI scan obtained by viewing the presence of certain specific markers in abnormal findings (especially tumors) inside the brain. Application has been developed on specific requirements of practice and it is user 
(doctor) - oriented, allows viewing and processing the results of MRI based on the specific requirements and needs. The application offers a variety of views - 2D model, 3D models, results in the form of graphs and DataGrids.

The application has been developed in collaboration with the University Hospital in Martin, its use is not limited to specific type of device, and it can also be used in other hospitals. It has been tested during the development based on results of volunteers in close collaboration with the University Hospital in Martin. Volunteers have been screened for in accordance with ethical and legal standards. CAT scans have been carried out under standard conditions MRI device Siemens Symphony 1.5 Tesla.

Based on the requirements, application offers the possibility to view the models on a computer with four monitors; data among windows are synchronized. The Figure 30 shows the 2D model (top left) and graph section (top right), the main window is situated in the left down part and the last one - right down part displays the 3D model.

This application offers new opportunities to process the results of MRI. The user gets the further information about the tumour location based on DICOM images. It is a significant improvement in brain tumour locating and processing. Chirurgeon can use these information for easier removing the tumour. Special mode for monitoring the progress of the treatment allows choosing the best treatment method for the patient.
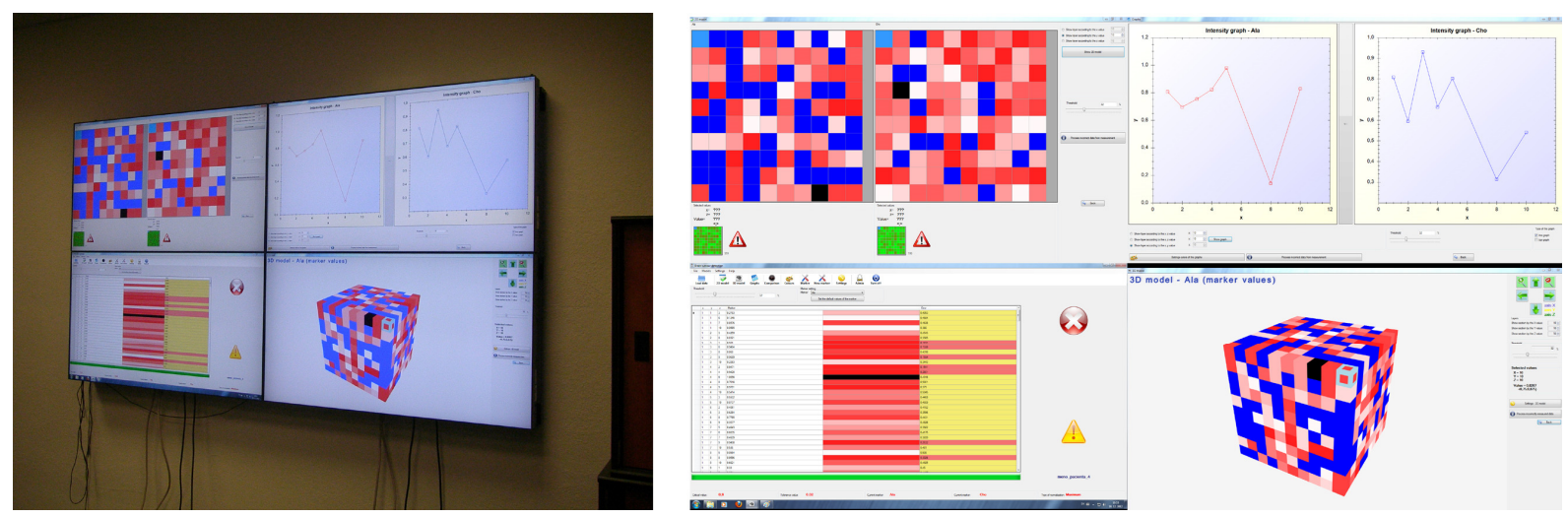

Figure 30. 4 monitors (Kvet, 2013)

\section{Conclusion}

Cancer is one of the most serious medical problems worldwide. Early diagnostics and adequate methods are key role for treatment of the patient.

The aim is to create a universal solution for processing the results of magnetic resonance imaging; to detect and locate brain tumors and provide results in the form of tables, graphs, 2D and 3D models based on user requirements. The aim of the application is to show the presence of markers - substances that are present in the tumor tissue. The application was designed to show the presence of both standard markers, but allows the user to enter additional markers based on the professional requirements (such as specific markers for predicting tumor type). It is also possible to save the results of magnetic resonance imaging and compare them in time. Application offers three languages - English, German and Slovak language allowing using it abroad.

The problem of the result processing magnetic resonance imaging is the measurement error in all investigated areas; some parts are measured with relatively high measurement error. Thus, we have created a module for processing the data in order to reduce measurement error and get the valid value of the referenced marker.

In a further development of the project, we will extend the database results, improve the new marker module and treatment methods to give the opportunity to compare and categorize different types of anomalies. We are going to expand the application to deal with anomalies in other organs of human body. 


\section{Acknowledgment}

This contribution is the result of the project implementation:

Centre of excellence for systems and services of intelligent transport II., ITMS 26220120050 supported by the Research \& Development Operational Programme funded by the ERDF.
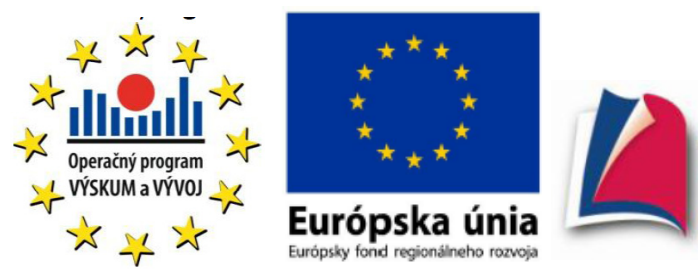

Agentúra

Ministerstva školstva, vedy, výskumu a športu SR pre štrukturálne fondy EÚ

Podporujeme výskumné aktivity na Slovensku/Projekt je spolufinancovaný zo zdrojov EÚ

This work was supported by the project Creating a new diagnostic algorithm for selected cancers, ITMS project code: 26220220022 co-financed by the EU and the European Regional Development Fund. The work is supported by the project VEGA 1/1116/11, Adaptive data distribution.

\section{References}

Dobeš, M. (2008). Zpracování obrazu an algoritmy vC\#. SK: BEN - technická literatúra.

Horvat, L. (2003). Digital Imaging: Essential Skills. Focal Press.

Hornak, J. (2008). The Basics of MRI, Interactive Learning Software.

Jähne, B. (2002). Digital Image Processing. Springer. http://dx.doi.org/10.1007/978-3-662-04781-1

James, S. (2010). 3D Graphics with XNA Game Studio 4.0. UK: Packt Publishing Ltd.

Kvet, M. (2012). Transformácia dát z magnetickej rezonancie hlavy pre 3D vizualizáciu. Diploma thesis, Žilina.

Kvet, M., \& Lieskovský, A. (2013). Temporal data management. In conference ICCGI proceeding, FR.

Kvet, M., \& Matiaško, K. (2013). Magnetic resonance imaging results processing. In Conference Digital Technologies 2013 proceeding. SK: Edis.

Kvet, M., \& Mešina, J. (2013). Brain tumour detection -3D model. In Conference ICTIC proceeding SK: Edis.

Kvet, M., Mešina, J., \& Matiaško, K. (2012). Algorithm for brain tumour detections. In Conference Acta electrotechnica et informatica proceesing. SK: TUKE.

Mešina, J. (2012). 3D vizualizácia mozgu človeka. Diploma thesis, Žilina.

Nekula, J. (2005). Radiologie. Univerzita Palackého.

Pianykh, O. (2008). Digital Imaging and Communications in Medicine. Springer.

Zeman, M. (2006). Speciální chirurgie. Galén.

\section{Copyrights}

Copyright for this article is retained by the author(s), with first publication rights granted to the journal.

This is an open-access article distributed under the terms and conditions of the Creative Commons Attribution license (http://creativecommons.org/licenses/by/3.0/). 